\title{
Das Verhältnis von Erfüllung, Schadensersatz und Vertragsaufhebung im CISG
}

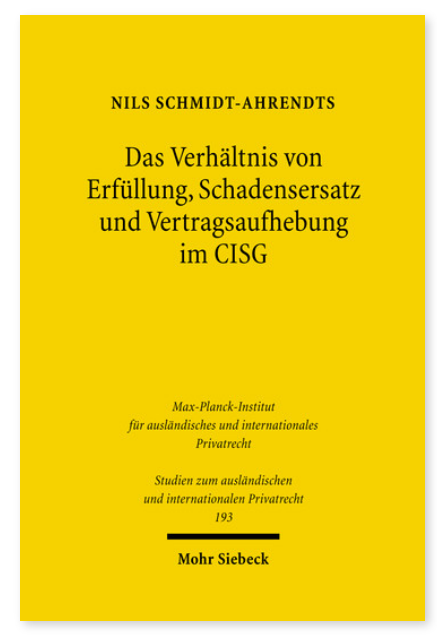

2007. XII, 190 Seiten. StudIPR 193

ISBN 978-3-16-151378-7

DOI 10.1628/978-3-16-151378-7

eBook PDF 59,00€

ISBN 978-3-16-149528-1

fadengeheftete Broschur 59,00€
Das Verhältnis von Erfüllung, Schadensersatz und Vertragsaufhebung im UN-Kaufrecht (CISG) ist geprägt durch das unterschiedliche Verständnis des civil und des common law. Nils Schmidt-Ahrendts untersucht die daraus resultierenden Auswirkungen auf die Ersatzfähigkeit der Mehrkosten von Deckungsgeschäften unter Berücksichtigung der dogmatischen Grundstruktur des CISG, des Gebots der Rechtssicherheit sowie des Gebots einer hinreichend flexiblen und wirtschaftlich angemessenen Lösung. Er kommt zu dem Ergebnis, dass das CISG den Gläubiger nur dazu berechtigt, unter der Bedingung der vorangehenden Vertragsaufhebung seinen Schaden anhand eines konkreten oder hypothetischen Deckungsgeschäfts zu berechnen. Hierdurch soll verhindert werden, dass er die erschwerten Voraussetzungen einer Vertragsaufhebung umgeht. Ein im CISG normiertes Gebot der Schadensminderung erlegt dem Gläubiger die Pflicht auf, nach wirksamer Vertragsaufhebung ein angemessenes Deckungsgeschäft vorzunehmen, verpflichtet inn jedoch weder dazu, bereits vor Vertragsaufhebung ein Deckungsgeschäft zu tätigen, noch dazu, durch eine frühzeitige Vertragsaufhebung die Voraussetzung für ein solches zu schaffen. Ebenso wenig gestattet das CISG dem Gläubiger, einen aus einem vorzeitigen Deckungsgeschäft entstandenen Differenzschaden zu liquidieren. Eine Ausnahme ist nur im Falle eines die Kosten des Deckungsgeschäfts übersteigenden Verzugsschadens sowie im Falle einer endgültigen und ernsthaften Erfüllungsverweigerung des Schuldners denkbar, nicht aber anlässlich eines sich allein ungünstig entwickelnden Marktpreises.

Nils Schmidt-Ahrendts Geboren 1979; Studium der Rechtswissenschaft in Freiburg und Grenoble; 2007 Promotion; Referendariat am OLG Hamburg.
Jetzt bestellen:

https://mohrsiebeck.com/buch/das-verhaeltnis-von-erfuellung-schadensersatz-und-vertragsaufhebung-im-cisg-

9783161513787?no_cache=1

order@mohrsiebeck.com

Telefon: +49 (0)7071-923-17

Telefax: +49 (0)7071-51104 